\title{
Optimal Pricing of a Duopoly Platform with Two-Sided Congestion Effect
}

\author{
Chokri Aloui ${ }^{1}$ and Khaïreddine Jebsi ${ }^{2}$ \\ ${ }^{1}$ Faculté de Droit et des Sciences Economiques et Politiques, Sousse, Tunisia \\ ${ }^{2}$ Institut supérieur de Gestion, Sousse, Tunisia
}

\begin{abstract}
We study, in this paper, the impact of two-sided congestion effect on the pricing policy of a twosided duopoly platform. Relative to Armstrong (2006), we show that, with congestion effect, (i) competition for submarket share is softened, (ii) the divide-and-conquer pricing strategy is modified insofar as it depends upon the differential of the marginal congestion costs and (iii) each platform charges any agent of one side a price that covers not only the marginal congestion cost that he imposes on agents of his own side having joined its platform, as the traditional principle of the textbook congestion pricing, but also it covers the marginal congestion cost that he indirectly imposes on the of-his-type agents having chosen to join the rival platform. This issue matters despite there is no technical link between the two platforms.
\end{abstract}

Keywords: Two-sided markets, duopoly, two-sided congestion effect, divide-and-conquer pricing strategy.

\section{Introduction}

It's well recognized that women and men need each other's attending in a nightclub. The higher the number of women a nightclub attracts, the higher will be the number of men adhering to such a club and vice versa. Since any nightclub offers a fixed area of a dance floor to the two genders simultaneously, each attendee feels boring when the number of his own type is increasing relative to that of the opposite sex. Nightclubs are considered as platforms, acting in a two-sided market where two distinct categories of consumers interact and share a fixed space. These two-sided platforms are characterized by negative direct network externalities taking the form of congestion or crowding effect insofar as agents of one side dislike the increasing number of agents of their own side. We call such congestion by two-sided congestion effect because it reaches the two sides simultaneously. Another example to note in this context is a shopping mall luring both retailers and buyers and it enables them to interact in a fixed settled-space. Buyers and retailers value each other but the satisfaction of any shopping mall agent decreases with respect to the overuse of the shopping mall' space by the of-his-own-type agents. Any two-sided platform characterized by such network externalities must take into account this effect when it charges prices to the two sides.

In addition to the negative direct network externalities, some platforms are

Copyright (C) 2011 Chokri Aloui and Khaïreddine. This is an open access article distributed under the Creative Commons Attribution License unported 3.0, which permits unrestricted use, distribution, and reproduction in any medium, provided that original work is properly cited. Contact Author: Chokri Aloui, e-mail: alouichokry2004@yahoo.fr 
characterized by negative indirect ones. These latter are linked to the fact that some agents of one side dislike the increasing participation of agents of the opposite side. For instance, more ads being placed in a journal or broadcast in a channel may represent a nuisance to some "eyeballs" notably the ad-avoiders.

The majority of the frameworks caring about two-sided markets has interested in studying the impact of their positive indirect network externalities (or cross-externalities) common feature on the platforms' pricing policies. The positive cross-externalities signify that agents of one side value more the increasing participation of agents belonging to the opposite side. For instance, cardholders (resp. merchants) are more incited to use (resp. to accept) Visa card when there are numerous merchants (resp. cardholders) who accept (use) it as a method of payment. Advertisers benefit from the audience of a magazine and ad-lovers readers value a magazine publishing more ads. The increasing number of Microsoft Windows applications developers enhances Microsoft Windows users' welfare and vice versa. There are many other examples that come to mind and that prove such a common feature of two-sided markets ${ }^{1}$. Platforms would earn positive profits if they manage "well" the two submarkets of agents. The pioneering frameworks in this context, such as Rochet and Tirole (2003 and 2006), Armstrong (2006), Hagiu (2006) among others, have studied the main characteristics of two-sided markets and they have let such an economic issue occupying an important place in the industrial organization literature.

By contrast, rare are the frameworks that have dealt with negative network externalities in two-sided markets ${ }^{2}$. Anderson and Coate (2005) have studied the negative indirect externalities. They address the case where viewers dislike ads while advertisers benefit from the increasing audience addressed to broadcasting channels. The result to note in their study is that, with two programmes, there exists a threshold of the nuisance cost such that the advertising level is lower (resp. higher) than the social optimal one as the nuisance cost is smaller (resp. larger) than a threshold.

Negative direct network externalities, the object of our paper, have been studied, in the two-sided markets context, by Belleflamme and Toulemonde (2009). These authors study the case where a certain "rivalry" effect characterizes one side of agents that are assumed to be homogenous with respect to their preferences for platforms. According to them, "rivalry" effect means that agents in one side compete with each other. For instance, merchants compete hard for trading with cardholders ${ }^{3}$.

Belleflamme and Toulemonde (2009) assume that there is an incumbent platform and a potential entrant that seeks entering the market. They analyze in what extent negative direct network externalities affect the pricing policy of the entrant in order to decide launching a new platform. They find that the two platforms cannot co-exist at the equilibrium.

Relative to the literature on two-sided markets, we aim, in this paper, to introduce negative direct network externalities taking the form of two-sided congestion effect. We attempt to analyze the impact of such a congestion effect on the pricing policy of a two-sided duopoly competing à-la Hotelling. The goal is to find out in what extent the crossexternalities change the pricing policies of a duopoly platform when two-sided congestion effect is present.

In fact, congestion goes in line with the "rivalry" effect studied by Belleflamme and Toulemonde (2009). By contrast to these latter, we interest, in our model, in studying the case where platforms are simultaneously active (co-exist) in the two-sided market and agents are heterogeneous with respect to their preferences for platforms. Furthermore, the simultaneous participation of the two groups of agents, sharing the same capacity, causes two-sided congestion effect. 
Armstrong (2006) has studied the case where agents are single-homers and there is no congestion. This author considers two platforms that compete with each other à-la Hotelling. The main finding to note in the Armstrong's framework is that positive indirect network externalities induce fierce competition for submarket share and therefore the so-called divide-and-conquer pricing strategy arises: each platform aims at targeting the side that represents the source of gain for the other.

In our paper, with two-sided congestion effects, we show, firstly, that competition between the two platforms is softened. The incentive of each platform as to attract the needed-more side is mitigated by the twosided congestion effect. Luring one agent to one side negatively affects the participation of agents of his own side and therefore the opposite side participation ${ }^{4}$. Secondly, the divide-and-conquer pricing strategy is modified insofar as the gap between the sides' prices depends on the differential of agents marginal congestion costs. Thirdly, the per-access price charged by each platform to one agent covers not only the marginal congestion cost that he imposes on the of-his-type agents joining his platform, like the traditional principle of the textbook congestion pricing, but also it covers the marginal congestion cost that he imposes on the agents of his own type having chosen to join the rival platform.

The rest of the paper is organized as follows. Section 2 presents the model. The Armstrong's result is briefly noticed in section 3. Section 4 analyzes the pricing policy of a duopoly platform with two-sided congestion effect. The last section concludes.

\section{The model}

Our model is given in a general setting so that the two sides are simply called "buyers" and "sellers". There are two platforms acting in a two-sided market. Each platform serves buyers, superscripted by $B$, and sellers, superscripted by $S$, and it enables them to transact (to meet). In order to let platforms differentiate solely by their "locations" in each submarket, we assume that they offer the same amount of capacity. We label such a capacity by the parameter $\Lambda>0$. Platform $i=1,2$ charges each group, $k=B, S$, a per-access price denoted by $p_{i}^{k}$. The platforms are located at the extremities of a linear distance of measure 1 so that platform 1 is located at 0 and platform 2 at 1 . Without loss of generality, we assume that the two groups are evenly distributed on the interval $[0,1]$ and they have a unit mass. The platforms incur a symmetric per- $k$-type cost denoted by $c^{k}$.

On the one hand, we suppose that buyers and sellers need each other and therefore they value their "meetings". On the other hand, we assume that each agent of one side dislikes the increasing number of the agents of his own side.

The utility function of agent $k$ adhering to platform $i$ is

$u_{i}^{k}=\theta^{k} N_{i}^{l}-p_{i}^{k}-e^{k} y_{i}^{k}$

where $\theta^{k}$ is the marginal value that a $k$-type places on an additional l-type. Such a parameter is assumed to be the same for all $k$-types (whether being subscribed to platform 1 or platform 2). So, $\theta^{k} N_{i}^{l}$ measures the network benefits for agent $k$ in platform i. The term $y_{i}^{k}=\frac{N_{i}^{k}}{\Lambda}$ is the congestion function ${ }^{5}$ of side $k$ in platform $i$, giving the level of congestion, where $N_{i}^{k}$ stands for the expected mass of group $k$ adhering to platform $i$. The parameter $e^{k}$ notates the willingness to pay of $i$-platform- $k$-type participant in order to avoid congestion (or his unit waiting cost) which is assumed to be also the same for all 
agents of side- $k$. So, the congestion cost born by agent $k$ in platform $i$ is given by $e^{k} y_{i}^{k}$.

The surplus of agent $k$ having chosen to adhere to platform 1 is

$$
S_{1}^{k}=u_{1}^{k}-t^{k} x^{k}
$$

and the surplus of agent $k$ having chosen to access to platform 2 is

$$
S_{2}^{k}=u_{2}^{k}-t^{k}\left(1-x^{k}\right)
$$

where $t^{k}$ is the so-called transportation cost or product differentiation parameter and $x^{k}$ (resp. $\left(1-x^{k}\right)$ ) indexes the preference of agent $k$ to platform 1 (resp. 2) . The term $t^{k} x^{k}$ (resp. $t^{k}\left(1-x^{k}\right)$ ) can be thought as the opportunity cost born by agent $k$ of having chosen platform 1 (resp. 2) while it's "ideal" is platform 2 (resp. 1).

The location of the marginal $k$-type who is indifferent between the two platforms is

$$
x^{k}=\frac{1}{2}+\frac{u_{1}^{k}-u_{2}^{k}}{2 t^{k}}
$$

The profit function of platform $i$ is ${ }^{7}$

$$
\pi_{i}=\left(p_{i}^{B}-c^{B}\right) N_{i}^{B}+\left(p_{i}^{S}-c^{S}\right) N_{i}^{S}
$$

In what follows, we adopt the following assumptions

$$
\text { Assumption A } \quad t^{k}>\theta^{k}-\frac{e^{k}}{\Lambda}
$$

Assumption A guarantees the submarket $k$ to be shared. We adopt this assumption as to avoid the fact that only one platform corners the two submarkets. Broadly speaking, we can learn from assumption A that agents' preferences for the platforms dominate (net) cross-externalities benefits ${ }^{7}$.

$$
\text { Assumption B } \quad 4 t^{B} t^{S}>\left(\theta^{B}+\theta^{S}\right)^{2}
$$

Assumption B ensures the concavity of the profit function $\pi_{i}(\cdot)$ with respect to prices $p_{i}^{B}$ and $p_{i}^{S}$.In order to analyze the pricing policy of a two-sided duopoly platform with two-sided congestion effect, we need to present in the following section the major results of Armstrong (2006) studying the pricing policy of two no-congested platforms competing à-la Hotelling.

\section{Duopoly pricing without two-sided congestion effect: a benchmark}

Armstrong (2006) has studied the pricing policy of a duopoly platform without congestion effect. He analyzes the case where the platforms compete with each other according to the Hotelling artifact and the two distinct groups are single-homers. The main results of Armstrong (2006) are given in the following lemma:

Lemma. For $k, l=B, S$ and $k \neq l$ and $i, j=1,2$ and $i \neq j$

The implicit $k$-market share

$N_{i}^{k}=\frac{1}{2}+\frac{\theta^{k}\left(2 N_{i}^{l}-1\right)+\left(p_{j}^{k}-p_{i}^{k}\right)}{2 t^{k}}$

The first order condition for symmetric equilibrium price charged to side $k$

$$
p^{k}=c^{k}+t^{k}-\frac{\theta^{l}}{t^{l}}\left(\theta^{k}+p^{l}-c^{l}\right)
$$


The symmetric equilibrium price charged to side $k$

$$
p^{k}=c^{k}+t^{k}-\theta^{l}
$$

Proof. See Armstrong (2006)

Armstrong shows that indirect network externalities result in a fierce competition for submarket share between the two platforms. He relates his finding to the fact that each platform seeks to lure more members in each side in order to "steer" all the submarkets from its rival. However, the divide-andconquer pricing strategy arises: each platform subsidizes the side that is "needed more" and it covers the loss on the other.

\section{Duopoly platform with two-sided congestion effect}

Now, we are ready to give our main results, taking into account two-sided congestion effect, in the following proposition

Proposition For $k, l=B, S$ and $k \neq l$; $i, j=1,2$ and $i \neq j$

The implicit $k$-market share of platform $i$ is

$$
N_{i}^{k}=\frac{1}{2}+\frac{\theta^{k}\left(2 N_{i}^{l}-1\right)+\left(p_{j}^{k}-p_{i}^{k}\right)}{2\left(t^{k}+\frac{e^{k}}{\Lambda}\right)}
$$

The equilibrium $k$-market share of platform $i$ is

$$
N_{i}^{k}=\frac{1}{2}+\frac{t^{l}\left(p_{j}^{k}-p_{i}^{k}\right)+\theta^{k}\left(p_{j}^{l}-p_{i}^{l}\right)}{2\left[\left(t^{B}+\frac{e^{B}}{\Lambda}\right)\left(t^{S}+\frac{e^{S}}{\Lambda}\right)-\theta^{B} \theta^{S}\right]}
$$

The first order condition for symmetric equilibrium price charged to side $k$ is

$$
p^{k}=c^{k}+t^{k}+\frac{e^{k}}{\Lambda}-\frac{\theta^{l}}{t^{l}+\frac{e^{l}}{\Lambda}}\left(\theta^{k}+p^{l}-c^{l}\right)
$$

The equilibrium symmetric price charged to side $k$ is

$p^{k}=c^{k}+t^{k}-\left(\theta^{l}-\frac{e^{k}}{\Lambda}\right)$

The equilibrium symmetric profit is

$$
\pi_{i}=\frac{t^{B}+t^{S}-\left(\theta^{B}-\frac{e^{B}}{\Lambda}\right)-\left(\theta^{S}-\frac{e^{S}}{\Lambda}\right)}{2}
$$

Proof.See Appendix

We can learn from the proposition the following

Expression (9) shows that the lure of an additional $l$-type to platform $i=1,2$ is accompanied by the attraction of $\frac{\theta^{k}}{t^{k}+\frac{e^{k}}{\Lambda}} k$-types to that platform. Such a fraction is lower the higher the marginal congestion cost on side $k, \frac{e^{k}}{\Lambda}$. Furthermore, we show that the fraction with congestion is lower than that without congestion, $\frac{\theta^{k}}{t^{k}}$. As a result, the positive network benefits are diminished by the within-side crowding.

In addition to the à-la Hotelling standard pricing result, $c^{k}+t^{k}$, we recognize that the access price charged by each platform to side $k$, given in (11), 
is adjusted upward by the marginal congestion cost that agent $k$ imposes on the of-his-type agents, $\frac{e^{k}}{\Lambda}$, and downward by the cross-externality related term $\frac{\theta^{l}}{t^{l}+\frac{e^{l}}{\Lambda}}\left(\theta^{k}+p^{l}-c^{l}\right)$. Compared with Armstrong (2006), this latter term, interpreted as the opportunity cost "of raising by enough the group- $k$ price to cause one group- $k$ agent to leave", is reduced. The opportunity cost is lower the higher the marginal congestion cost that any l-type agent imposes on the $l_{s}, \frac{e^{l}}{\Lambda}$. Indeed, the network benefit that any agent brings to the opposite group is reduced due to congestion effect because luring one type to one group negatively affects the participation of his group and therefore the participation of the opposite one. Platforms take into consideration the interplay between the negative direct and positive indirect externalities.

$\checkmark$ Relative to Armstrong (2006), expressions (12) and (13) demonstrate that two-sided congestion effect softens the competition between platforms for submarket share in the sense that their capability to compete is limited due to the reduction of the network benefits. For instance, in peak periods, some shopping malls monitor the adhesion of both buyers and sellers and they tend to ban the entry of the additional ones.

It follows from the proposition two corollaries that go into our analysis in depth.

Corollary 1: The gaps between the sides' prices $\left(p^{B}-p^{S}\right) \quad$ with and without congestion are, respective

$$
\begin{gathered}
\Delta p^{C}=\left(c^{B}-c^{S}\right)+\left(t^{B}-t^{S}\right)+\left(\theta^{S}-\theta^{B}\right)+\frac{1}{\Lambda}\left(e^{B}-e^{S}\right) \\
\Delta p=\left(c^{B}-c^{S}\right)+\left(t^{B}-t^{S}\right)+\left(\theta^{S}-\theta^{B}\right)
\end{gathered}
$$

Proof. Based on expressions (8) and (12), corollary 1 is omitted

Compared with Armstrong (2006), we show that, with congestion, the divide-and-conquer pricing strategy is modified insofar as the gap between sides' prices depends on the sign of the differential of the agents unit waiting $\operatorname{costs}\left(e^{B}-e^{S}\right)$. If the latter differential is positive (resp. negative), each platform tends to "divide" more (resp. less) one side.

Corollary 2: Expression (11) can be rewritten as

$$
p_{i}^{k}=c^{k}+t^{k}-\theta^{l}+e^{k} N_{i}^{k}\left(\frac{1}{\Lambda_{i}}+\frac{1}{\Lambda_{j}}\right)
$$

Proof. Taking into account that the two platforms share the two submarkets equally at a symmetric equilibrium and admitting that the platforms have the same amount of capacity, corollary 2 is omitted.

Corollary 2 raises a new interesting result that has not been afforded attention in the literature studying congestion pricing. We show that the per-access price charged by each platform $i$ to a $k$-type agent covers not only the marginal congestion cost that he imposes on the of-his-type agents having accessed to that platform $\frac{e^{k}}{\Lambda_{i}}$, like the traditional principle of the textbook congestion pricing, but also it covers the marginal congestion cost that he imposes on 
agents of his own type having chosen to join platform $j, \frac{e^{k}}{\Lambda_{j}}$. Indeed, since all $k$-type agents have the same willingness to pay in order to avoid congestion, when a $k$-type chooses to join platform $i$, he limits the choice of the other agents of his side because he makes this platform less attractive for them, and therefore he urges them to join platform $j$. He thus indirectly imposes a congestion cost on the $k$-type agents having adhered to platform $j$ despite there is no technical link between the two platforms.

\section{Conclusion}

We have studied in this paper the optimal pricing of a two-sided duopoly when the two sides are characterized by congestion. The motivation to study the two-sided congestion effect is related to the fact that it is not always the case that cross-externalities benefits are the main "gift" two-sided platforms offer to the groups in order to get them together. It will be also optimal to attract the adequate number of gift-sharers. We have shown that with congestion effect, the divide-and-conquer pricing strategy is modified and therefore the competition for attracting more members of the two distinct groups is "calm". In addition, each agent pays both the marginal congestion cost that he directly imposes on agents of his own type joining his platform and that he indirectly imposes on agents of his own type joining the rival platform. The indirect one is linked to the fact that each agent, while choosing any platform, urges some other agents of his type to choose the rival platform.

For further research, one can analyze the cases where (i) platforms differentiate not only by their "locations" but also by the capacities they offer(ii) agents of one side are heterogeneous with respect to their preferences to the opposite side and (iii) agents belonging to the same side have different willingness to pay in order to avoid congestion.

\section{Appendix}

\section{Proof of the proposition}

Using (1) and (4), we get

$$
x^{k}=\frac{1}{2}+\frac{\theta^{k}\left(N_{1}^{l}-N_{2}^{l}\right)+\frac{e^{k}}{\Lambda}\left(N_{2}^{k}-N_{1}^{k}\right)+\left(p_{2}^{k}-p_{1}^{k}\right)}{2 t^{k}}
$$

Taking into account the fact that $N_{2}^{k}=1-N_{1}^{k}$, we obtain

$$
x^{k}=\frac{1}{2}+\frac{\theta^{k}\left(2 N_{1}^{l}-1\right)+\frac{e^{k}}{\Lambda}\left(1-2 N_{1}^{k}\right)+\left(p_{2}^{k}-p_{1}^{k}\right)}{2 t^{k}}
$$

Assuming the expected $k$-submarket share of platform 1 is fulfilled, that is $x^{k}=N_{1}^{k}$, we easily obtain expression (9) in the proposition for $i=1$. We deduce expression (9) for $i=2$ taking into account that $N_{2}^{k}=1-N_{1}^{k}$.

It follows from expression (9) the following system 


$$
\left\{\begin{array}{l}
2\left(t^{B}+\frac{e^{B}}{\Lambda}\right) N_{i}^{B}-2 \theta^{B} N_{i}^{S}=t^{B}+\frac{e^{B}}{\Lambda}-\theta^{B}+\left(p_{j}^{B}-p_{i}^{B}\right) \\
-2 \theta^{S} N_{i}^{B}+2\left(t^{S}+\frac{e^{S}}{\Lambda}\right) N_{i}^{S}=t^{S}+\frac{e^{S}}{\Lambda}-\theta^{S}+\left(p_{j}^{S}-p_{i}^{S}\right)
\end{array}\right.
$$

The resolution of the above system gives expression for $k, l=B, S ; k \neq l$ and $i, j=1,2 ; i \neq j$.

The profit function of platform $i=1,2$ is

$$
\pi_{i}=\left(p_{i}^{B}-c^{B}\right) N_{i}^{B}\left(p_{1}^{k}, p_{2}^{k}\right)+\left(p_{i}^{S}-c^{S}\right) N_{i}^{S}\left(p_{1}^{k}, p_{2}^{k}\right) ; k=B, S
$$

where $N_{i}^{k}(\cdot)$ is given in (10).

The objective of platform $i=1,2$ is to solve the following maximization program

$$
\max _{p_{i}^{B}, p_{i}^{S}} \pi\left(p_{i}^{B}, p_{i}^{S}\right)
$$

The F.O.C result in the following system

$$
\left\{\begin{array}{l}
\frac{1}{2}+\left[t^{S}\left(p_{j}^{B}-p_{i}^{B}\right)+\theta^{B}\left(p_{j}^{S}-p_{i}^{S}\right)-t^{S}\left(p_{i}^{B}-c^{B}\right)-\theta^{S}\left(p_{i}^{S}-c^{S}\right)\right] \Theta=0 \\
\frac{1}{2}+\left[t^{B}\left(p_{j}^{S}-p_{i}^{S}\right)+\theta^{S}\left(p_{j}^{B}-p_{i}^{B}\right)-t^{B}\left(p_{i}^{S}-c^{S}\right)-\theta^{B}\left(p_{i}^{B}-c^{B}\right)\right] \Theta=0
\end{array}\right.
$$

where $\Theta=2\left[\left(t^{B}+\frac{e^{B}}{\Lambda}\right)\left(t^{S}+\frac{e^{S}}{\Lambda}\right)-\theta^{B} \theta^{S}\right]>0$ given assumption A.

Assuming a symmetric equilibrium, that is $p_{1}^{k}=p_{2}^{k}=p^{k}$, we obtain

$$
\left\{\begin{array}{l}
\frac{1}{2}-\left[t^{S}\left(p^{B}-c^{B}\right)+\theta^{S}\left(p^{S}-c^{S}\right)\right] \Theta=0 \\
\frac{1}{2}-\left[t^{B}\left(p^{S}-c^{S}\right)+\theta^{B}\left(p^{B}-c^{B}\right)\right] \Theta=0
\end{array}\right.
$$


Each equation of the above system allows us to obtain expression (11) in the proposition for $k, l=B, S$ and $k \neq l$. We can re-write the latter system as follows

$$
\left\{\begin{array}{l}
t^{S}\left(p^{B}-c^{B}\right)+\theta^{S}\left(p^{S}-c^{S}\right)=\frac{\Theta}{2} \\
\theta^{B}\left(p^{B}-c^{B}\right)+t^{B}\left(p^{S}-c^{S}\right)=\frac{\Theta}{2}
\end{array}\right.
$$

The resolution of the system allows us to easily obtain the equilibrium symmetric prices defined in expression (12) in the proposition for $k, l=B, S$ and $k \neq l$. The equilibrium exists because the Hessian matrix

$$
H=\left(\begin{array}{cc}
-\frac{2 t^{S}}{\Theta} & -\frac{\left(\theta^{B}+\theta^{S}\right)}{\Theta} \\
-\frac{\left(\theta^{B}+\theta^{S}\right)}{\Theta} & -\frac{2 t^{B}}{\Theta}
\end{array}\right)
$$

is negative semi-definite in the case where assumptions $A$ and $B$ are met.

Finally, it's easy to obtain (13) by inserting (12) in expression (5) (the symmetric equilibrium submarket shares are equal $\frac{1}{2}$ ).

\section{Endnotes}

${ }^{1}$ For more examples of two-sided platforms see Evans (2003), among others.

2 The one-sided congestion effect in twosided markets setting is also studied by Aloui and Jebsi (2008). Their model concerns commercial fairs and clinics in which the side of buyers (whether visitors or patients) is congested and the sellers' (whether exhibitors or doctors) is not.

${ }^{3}$ Austin Frakt (2009) argues that "relative to the old parity pricing system, if women pay less than men to enter Dude's Club, they are both more willing to attend and to have a better time". Consequently, what Austin Frakt claims about Dude's club is not always true.
${ }^{4}$ See Reitman (1991) for the formulation of congestion functions of different forms of congestion in particular for the processor sharing.

5The expected submarkets shares of the platforms are assumed to be fulfilled i.e. $x^{k}=N_{1}^{k}$ and $\left(1-x^{k}\right)=N_{2}^{k}$

${ }^{6}$ If the reverse case holds .i.e. $t^{k}<\theta^{k}-\frac{e^{k}}{\Lambda}$, all $k$-agents choose the platform having the larger l-submarket share and therefore that platform corners the two-sided market.

${ }^{7}$ If the reverse case holds .i.e. $t^{k}<\theta^{k}-\frac{e^{k}}{\Lambda}$, all $k$-agents choose the platform having the larger $l$-submarket share and therefore that platform corners the two-sided market. 


\section{References}

Aloui, C. and Jebsi, K. (2008), "Optimal pricing of a two-sided monopoly platform with one-sided congestion effect", $57^{\text {th }}$ conference of AFSE, Paris.

Anderson, SP. and Coate, S. (2005), "Market provision of broadcasting: a welfare analysis", The Review of Economic Studies (72), 947-972.

Armstrong, M. (2006), "Competition in twosided markets", Rand Journal of Economics (37), 668-691.

Belleflamme, P. and Toulemonde, E. (2009), "Negative intra-group externalities in twosided markets", International Economic Review (50), 245-272.

De Palma, A. and Leruth, L. (1989), "Congestion and game in capacity: a duopoly analysis in the presence of network externalities", Annales d'Economie et de Statistique (15)/(16), 389-407.

Hagiu, A. (2004), "Two-sided platforms: pricing and social efficiency", RIETI Discussion Paper Series 04-E-035, Research
Institute of Economy Trade and Industry, Japan.

Evans, D. (2003), "The antitrust economics of multi-sided platform markets", Yale Journal on regulation, (20), 325-382.

Frakt, A. (2009), "Two-sided markets, part I: Gender-based price discrimination at the nightclub, in the "Incidental Economist". [Online], http:\\theincidentaleconomist.com

Reitman, D. (1991), "Endogenous quality differentiation in congested markets", The Journal of Industrial Economics (39), 621647.

Rochet, JC. and Tirole, J. (2003), "Platform competition in two-sided markets", Journal of the European Economic Association (1), 9901029.

Rochet, JC. and Tirole, J. (2006), "Two-sided markets: A Progress Report", Rand Journal of Economics (37), 645-667.

Scotchmer, S. (1985), "Two-tier pricing of shared facilities in a free-entry equilibrium", Rand Journal of Economics (16), 456-472. 